\title{
REVIEW
}

\section{Feasting on microplastics: ingestion by and effects on marine organisms}

\author{
Chidi Onyema Egbeocha ${ }^{1, *}$, Sorayya Malek ${ }^{1}$, Chijioke Uche Emenike ${ }^{2}$, Pozi Milow ${ }^{1}$ \\ ${ }^{1}$ Institute of Biological Sciences, Faculty of Science, University of Malaya, 50603 Kuala Lumpur, Malaysia \\ ${ }^{2}$ Department of Biological Sciences, Hezekiah University, Nkwerre, Imo State, Nigeria
}

\begin{abstract}
Ingestion of microplastics by marine organisms is a common occurrence in marine ecosystems, but the experimental demonstration of the effects of ingested microplastics on marine organisms has only recently become an important subject of research. In this review, the ingestion of microplastics by marine organisms, its attendant potential consequences and specific hypothetical questions for further studies are discussed. The formation of heteroaggregates in the gut of prey organisms may delay microplastic clearance, potentially increasing the chances of microplastic trophic transfer to predators. Also, the survival and energetics of keystone species at lower trophic levels are negatively affected by ingestion of microplastics, thereby raising questions about the transfer of energy and nutrients to organisms at higher trophic levels. Further, since microplastics are able to adsorb and concentrate organic pollutants up to 1 million times more than the pollutant concentration in ambient waters, the ingestion of such small plastic fragments is, a probable route for the entrance and biomagnification of toxic chemicals in the marine food web. However, the equilibrium state between pollutant concentration in marine organisms and that of surrounding waters makes it unclear whether the ingestion of microplastics actually increases the pollutant load of organisms. Finally, microplastic ingestion can cause endocrine disorders in adult fish, which could result in neoplasia via epigenetic programming. Therefore, microplastic pollution may be a contributory cause of increased incidents of neoplasia in marine animals. The amount of microplastics in marine waters will steadily rise, and questions about their impact on marine ecosystems will linger.
\end{abstract}

KEY WORDS: Microplastics - Ingestion - Marine organisms - Persistent organic pollutants · Trophic transfer $\cdot$ Biomagnification $\cdot$ Marine food web $\cdot$ Marine wildlife cancer

\section{INTRODUCTION}

Over the past century, petroleum-derived synthetic plastic polymers have been widely used, and due to the characteristics of plastic, such as being lightweight and having high durability, these polymers from numerous sources are finding their way into fresh and marine water bodies. About 335 million metric tons of plastic products were manufactured in

\footnotetext{
*Corresponding author: chidiegbeocha@gmail.com
}

2016 (PlasticsEurope 2017). This enormous global plastic production creates a problem associated with disposing of the material, and as a result, the disposal of plastic waste has directly or indirectly led to the transfer of a considerable amount of plastics into marine ecosystems. Although plastics are of immense benefit to society, the negative side to our 'plastic age' is increasingly becoming a source of concern. Once plastics are discarded into the envi- 
ronment, they are subjected to environmental conditions such as sunlight, oxidation, abrasion etc., and over a long period of time, they begin to fragment into smaller plastic particles that are loosely referred to as microplastics (Erren et al. 2013).

Microplastics are widely reported to impact the biotic components of marine ecosystems; however, their interaction with abiotic components like marine chemical contaminants can have significant consequences for marine biota. Since it was first reported that polypropylene micro-particles readily adsorb hydrophobic organic compounds (Rice \& Gold 1984), the interaction between microplastics and marine chemical pollutants has attracted considerable attention. Marine waters act as sinks for persistent organic pollutants (POPs) such as polychlorinated biphenyls (PCBs) and polybrominated diphenyl ethers. Although the hydrophobicity of these contaminants makes them sparingly soluble in water, it also makes these chemical pollutants preferentially adsorb onto microplastics. Consequently, microplastics are regarded as harmful pollutants (Teuten et al. 2007).

The large surface area to volume ratio of microplastics further increases their capacity to accumulate and transport organic contaminants that are abundant in marine waters. Contaminants adsorbed onto microplastics can desorb from the debris. The desorption rate of sorbed contaminants from microplastics increases with an increase in the surface area to volume ratio of the micro-particles (Teuten et al. 2009). Therefore, while marine organisms may not take up significant amounts of POPs directly from surrounding waters, ingesting microplastics with sorbed contaminants may be partly responsible for the uptake of bioaccumulative contaminants in marine organisms. The wide variety of colors, shapes and sizes of microplastics may determine not only what organisms intentionally or unknowingly consume them, but also whether the plastic particles are taken up by the cells and tissues of the organisms that ingest or interact with them (Boerger et al. 2010, Brennecke et al. 2015).

\section{Phytoplankton interaction with microplastics}

As primary producers at the base of most marine trophic pyramids, phytoplankton form an important food source for many marine organisms. They also constitute the bulk of marine snow, which is important organic matter that is required to maintain the metabolism of marine benthos. Phytoplankton such as algae can potentially interact with microplastics in such a way that has consequences for both the organism and the micro-debris. Algae in the marine environment are capable of forming heteroaggregates with microplastics, and this could influence the vertical distribution and sedimentation rate of microplastics in the water column (Long et al. 2017). Aggregate formation between microplastics and algae in the water column increases the sinking rate and reduces the residence time of microplastics in the marine environment. This raises questions about the fate of microplastics in the water column as well as the sediment incorporation rate of the microparticles. Furthermore, the interaction between microplastics and phytoplankton can interfere with zooplankton feeding, because phytoplankton is an important food source for most planktonic animals. Indeed, heteroaggregate formation has reportedly led to a higher microplastic ingestion rate among zooplankton (Ayukai 1987). This in turn could further make microplastics bioavailable to predatory and filterfeeding organisms at higher trophic levels.

While the interaction between microplastics and phytoplankton may increase the sinking and sedimentation rates of the plastic microdebris, the chlorophyll concentration, photosynthesis, cell population growth, gene expression, colony size and morphology of phytoplankton could be drastically altered by microplastic aggregation (Yokota et al. 2017). Additionally, the size of microplastic particles affects the extent to which these alterations occur; hence, the smaller the microplastic, the greater its negative impacts on phytoplankton (Zhang et al. 2017). However, most interactions between microplastics and phytoplankton have been demonstrated in laboratory experiments, so it has yet to be determined whether such interactions are actually occurring in marine seston.

\section{Microplastics in the benthic environment}

The marine benthic environment is increasingly becoming a reservoir for microplastic debris, especially those plastic particles that are composed of positively buoyant polymers. Since the density of many plastic polymers is lower than that of seawater, they float in the marine environment; however, the relative density of floating microplastic may increase during its residence time in marine waters (Wang et al. 2016). Plastic microparticles that are denser than seawater sink and settle on the ocean floor, but microplastics that are less dense than seawater have also been found to eventually sink to the 
benthic environment due mainly to fouling by microorganisms (Fazey \& Ryan 2016). Over a period of weeks to a few months, biofouling could lead to an increase in the density of positively buoyant microplastics until the density of the microplastics reaches or exceeds that of seawater. This would in turn cause microplastics to become submerged in the water column, either as neutrally drifting or slowly sinking particles. Therefore, biofouling may lead to the incorporation of microplastics into marine benthic sediments. Smaller plastic particles with a larger surface area to volume ratio more easily lose their buoyancy and sink sooner than larger fragments (Ryan 2015). Furthermore, microplastics may also sink to the benthic environment with the fecal pellets of zooplankton and other organisms that readily ingest and egest the micro-debris (Cole et al. 2016). Indeed, zooplankton fecal pellets play an important role as a biological pump that transports particulate organic matter, nutrients, carbon and energy to deeper waters and sediments. This top-down movement of fecal materials can also facilitate the transfer of anthropogenic chemical pollutants such as polycyclic aromatic hydrocarbons and hydrocarbon petroleum residues to deeper waters. Consequently, the ocean floor has become a major repository for microplastic debris and organic pollutants (Woodall et al. 2014).

A number of studies have demonstrated the abundance of microplastics in marine shallow sediments (Claessens et al. 2011, Alomar et al. 2016) and in deep-sea sediments (Woodall et al. 2014, Fischer et al. 2015). In sediments off the coast of Belgium, concentrations of microplastics were 15 to 50 times higher than reported maximum concentrations of other similar study areas (Claessens et al. 2011). The study indicated that the distribution of microplastics in marine sediment is related to the proximity of urban centers to marine environments, as well as the intensity of industrial, maritime and recreational activities.

Once microplastics are incorporated into marine sediment, they become bioavailable to benthic dwelling organisms. This may have consequences for the benthic food web because sedimented microplastics may be ingested by benthic organisms, eventually resulting in the trophic transfer of fragmented plastic debris. Furthermore, the ingestion of sedimented microplastics by marine benthos may potentially lead to further accumulation and biomagnification of marine chemical pollutants that could have adsorbed onto the micro-debris that gets transported to the ocean floor.

\section{INGESTION OF MICROPLASTICS}

Ingestion is the most likely way by which marine fauna interact with microplastics, especially when the feeding mechanisms of the organisms are nondiscriminatory and do not allow them to differentiate between food and plastic fragments (Lusher et al. 2016). Consequently, a large number of filter feeding organisms such as copepods, bivalves, fish and whales could actively target, or passively ingest, microplastics floating in surrounding waters (Lusher 2015). The small size of microplastics makes them even more likely to be ingested by a wide range of marine biota in pelagic and benthic ecosystems. Moreover, due to variations in size, shape and color of small plastic fragments, marine organisms may mistake microplastics for prey, thereby feeding on them directly. Although the ingestion of microplastics may be largely attributed to the ubiquitous nature of plastic micro-debris and the inability of many marine fauna to differentiate between food and non-food items, some marine animals ingest microplastic debris because they find it palatable (Allen et al. 2017). Microplastic ingestion affects organisms at all trophic levels, and the amount of microplastic ingested by marine organisms may vary between location and species. This variation can be significant even within the same area (Nadal et al. 2016).

\section{Bivalve mollusks}

Filter-feeding bivalve mollusks have been reported to ingest microplastics in their natural environment (Van Cauwenberghe et al. 2015) and in laboratory experiments (von Moos et al. 2012, Xu et al. 2017). Although microplastics are often egested within hours of being consumed by many marine organisms, the micro-debris has been observed in the gills, digestive glands, stomach and circulatory system of bivalves (Browne et al. 2008, von Moos et al. 2012). In fact, ingested microplastics that translocate to the circulatory system of bivalve mollusks can remain in the hemolymph of the organism for up to $48 \mathrm{~d}$. Thus, more than simply ingesting microplastics, some bivalves may accumulate them for prolonged periods of time with the risk of adverse consequences.

Factors such as insufficient food sources and abundance of microplastics in the habitat of bivalves may be responsible for the ingestion of microplastics by these organisms. However, it is possible that mussels, in comparison to other marine invertebrates, may ingest much less microplastic debris in their natural 
environment. This is mainly due to the organisms' preferential feeding mechanism which enables them to reject nonfood particles as pseudo-feces, i.e. materials that are rejected before ingestion but cleared from suspension (Ward \& Shumway 2004). Additionally, bivalves possess selection mechanisms like preferential clearance on the ctenidia, pre-ingestive selection on the labial palps, post-ingestive selection in the stomach and differential absorption in the gut (Brillant \& MacDonald 2000). Therefore, the following questions have not been clearly answered: (1) How are microplastics ingested by the organisms despite their preferential/selective feeding mechanisms? (2) How does the micro-debris accumulate in the gut? (3) How do microplastics translocate into the circulatory system of bivalve mollusks?

Since bivalves are an important food source for a variety of marine predators as well as humans, contaminated organisms can transfer microplastics to predators that feed on them, including humans. Indeed, bivalve mollusks that were specifically reared in the Atlantic Ocean and the North Sea for human consumption contained microplastics in their tissues (Mathalon \& Hill 2014, Van Cauwenberghe \& Janssen 2014). Even after $72 \mathrm{~h}$ of depuration, the organisms still contained microplastics in such proportions that could translate into an annual dietary exposure of 11000 microplastic particles $\mathrm{yr}^{-1}$ for European shellfish consumers. So despite depuration, bivalves are able to retain ingested microplastics for an extended period of time (Mathalon \& Hill 2014). This poses the challenge of ridding bivalves of ingested microplastics, as well as cultivating the organisms without the risk of microplastic contamination.

\section{Zooplankton}

Zooplankton play a vital role in determining the trophic structure of many marine ecosystems; as a result, they form a key biotic component of the marine environment. As both primary and secondary consumers near the base of the marine food pyramid, zooplankton are themselves an important food source for numerous organisms that either actively capture them, or consume the planktonic animals by filtering large volumes of water. Therefore, zooplankton constitute an essential link between phytoplankton and large open-ocean animals (Sailley et al. 2015).

The ingestion of microplastics by zooplankton to a large extent depends on the concentration and the size of the microplastic particles (Setälä et al. 2014). When the concentration of microplastics is high, zooplankton ingestion of the micro-debris is correspondingly high; however, larger microplastics are less likely to be ingested by the organisms than smaller ones. The size-based selection of microplastics by zooplankton also depends on the size of the organism; hence, larger zooplankton ingest larger pieces of microplastic and vice versa.

Furthermore, the size of microplastics that grazing zooplankton are capable of ingesting in turn depends on the feeding mechanism of individual zooplankton. Most taxonomically described zooplankton graze by generating feeding currents through the movement of their swimming legs and appendages. The feeding current indiscriminately draws potential food items, which may include microplastics, in the general direction of the organism (Cole et al. 2013, Setälä et al. 2016). Prey or microplastic retrieval may either be by direct interception, or by straining the particles out of the feeding current. Retrieval may also be by perceiving and capturing potential prey items that arrive in the feeding current (Kiørboe 2011).

Interestingly, when compared to the size of microplastics ingested by zooplankton in laboratory experiments, zooplankton in their natural environment appear to ingest much larger plastic fragments (Cole et al. 2013, Sun et al. 2017). The ingestion of larger plastic fragments by organisms in their natural environment may have implications on the survival and energetics of the organism, and such effects may not be captured in laboratory experiments. Zooplankton ingestion of microplastics indicates that organisms near the base of marine food pyramids mistake microplastics for food, raising questions of the potential for trophic transfer to predatory species at higher trophic levels.

Although most published materials on the ingestion of microplastics by zooplankton are based on laboratory experiments, there is evidence that zooplankton in their natural habitats also ingest plastic micro-debris. In fact, a staggering $61 \%$ of zooplankton sampled off the Portuguese coast were found to have ingested microplastics (Frias et al. 2014).

It is not known how long ingested microplastics had been retained in wild zooplankton before they were captured and analyzed, but it is likely that zooplankton in the wild retain microplastics longer than in experimental settings. The ingestion and retention of microplastics by zooplankton may depend on the availability of food, such that when food is in short supply, zooplankton ingest more microplastics and retain the ingested micro-particles much longer 
(Kaposi et al. 2014). A longer retention increases the chances of microplastic transfer from zooplankton to predatory organisms at higher trophic levels. Insight into how long zooplankton and other marine organisms in the wild retain ingested microplastics is important for researchers to further study the leaching of plastic additives as well as the desorption of persistent, bioaccumulative and toxic contaminants that may be associated with microplastics.

\section{Meroplankton}

The larval forms of some marine organisms, including sea urchins, crustaceans, sea stars, most fishes, some marine snails and marine worms, constitute an important group of zooplankton that are generally known as meroplankton. Meroplankton in the marine environment, like many other marine organisms, are not shielded from microplastic ingestion, and because microplastics persist in marine waters over a long period of time, marine larvae are chronically exposed to the debris. However, the exposure of meroplankton to microplastics over a prolonged period may not necessarily lead to an increase in microplastic ingestion (Kaposi et al. 2014, Mazurais et al. 2015). The reduced microplastic ingestion rate by chronically exposed marine larvae may in part be due to the formation of biofilm on the surface of the plastic particles, but the absence of a food source such as microalgae could lead to a drastic increase in microplastic ingestion (Kaposi et al. 2014).

Also, the size of meroplankton likely plays a role in determining both the quantity and size of ingested microplastics. Smaller larval organisms ingest only the smallest microplastics, but they usually contain a greater microplastic load in comparison to larger larvae, which are capable of ingesting both smaller and larger plastic particles. Microplastics that are ingested by marine larvae in laboratory experiments are often egested after a few hours, and harmful effects such as gut obstruction, impaired larval development or reduced feeding capacity may not be measurable consequences of microplastic ingestion by meroplankton (Kaposi et al. 2014).

Laboratory demonstrations of microplastic ingestion by marine larvae typically employ high microplastic concentrations, but even in natural marine environments where microplastic concentration is much lower, meroplanktonic organisms such as fish larvae still ingest plastic micro-debris. Microplastic ingestion by meroplankton in their natural environment may be directly related to microplastic abun- dance further offshore. The abundance of microplastics and the incidence of microplastic ingestion were reported to decrease with increasing distance from the coast, while the density of fish larvae increased with increasing distance from the coast (Steer et al. 2017).

\section{Non-planktonic crustaceans}

Many large crustaceans such as the Norway lobster Nephrops norvegicus, a benthic dwelling decapod, are 'messy' feeders and are characteristically unable to recognize and discard plastic filaments that are associated with their food. Therefore, in their natural environment, these crustaceans ingest large amounts of microplastic particles. Crustaceans are exposed to microplastics through feeding and potentially through burrowing activities. As a result, the likely entry route for microplastics reported in these animals is either via passive ingestion with sediments during feeding and burrowing, or through the ingestion of microplastic-contaminated prey, i.e. via trophic links (Welden \& Cowie 2016).

Factors such as sex, size and molt stage influence the retention of microplastics in lobsters (Welden \& Cowie 2016), and female lobsters retain more microplastic particles than males. Females molt less frequently than males, and this may be partly responsible for the greater retention of microplastics in female lobsters. Post-molt individuals of $N$. norvegicus contained no microplastics in the foregut, whereas the foregut of individuals that had not yet molted contained an aggregation of microplastics (Welden \& Cowie 2016). The significantly lower weight of microplastics in recently molted individuals implies that $N$. norvegicus rid themselves of plastic aggregations when they molt. It is, however, interesting to note that there were no reports of the presence of microplastics in the exuviae of recently molted individuals, raising questions about the fate of the microplastics that are removed when the organism molts. Nevertheless, molting clearly plays an important role in microplastic removal from lobsters, although the process needs to be investigated further.

Mysid shrimps ingest microplastics to varying degrees, and free-swimming crustaceans ingest more microplastics compared to sessile ones (Setälä et al. 2016). Mysid shrimps are omnivorous, feeding on detritus, phytoplankton and zooplankton. Considering that some microplastics may sediment out of the water column for reasons like biofilm formation and 
aggregation to organic substances, sedimented plastic particles may become bioavailable to shrimps that feed actively on detritus on the ocean floor. Moreover, since shrimps are able to switch their feeding behavior between 2 habitats, for example between the sediment and the water column, they may be prone to ingesting microplastics both in the water column and in the sediment, and this could lead to a greater accumulation of microplastic particles in the organism.

Like many other crustaceans, amphipods naturally feed on phytoplankton, zooplankton and other decomposing materials, while also ingesting sediment surface. As nocturnal swimmers that stay in sediment burrows during the day and swim actively in the water column at night, amphipods may be uniquely exposed to microplastics in their planktonic prey, in sediment and in the water column. Nocturnal organisms afford a peculiar opportunity to study the effects of vision on the ingestion of microplastics, as it is yet to be determined whether organisms that graze at night accidentally ingest more microplastics than those that feed during the day.

Other crustaceans such as crabs with comparable feeding behaviors to $N$. norvegicus may act as both carnivores and scavengers, and may take up microplastics during feeding or burrowing activities. As a result of their feeding behavior, crabs could be at a similar risk of microplastic loading as $N$. norvegicus. Microplastics ingested by crabs could be transferred to and accumulate in organs such as the hepatopancreas and gills. The presence of these potentially harmful particles in vital organs could have health implications for the animals (Brennecke et al. 2015). The predatory behavior of crabs can lead to the consumption of microplastic-contaminated prey, and such trophic transfer of microplastics to crabs has resulted in the retention of the debris for up to $3 \mathrm{wk}$, thereby increasing the chances of further trophic transfer of microplastics to higher trophic-level animals that prey on crabs (Farrell \& Nelson 2013). While there may be limited studies on the ingestion of microplastics by crabs in their natural environment, a quarter of the samples of the invasive portunid crab Charybdis longicollis from the Eastern Mediterranean were reported to have ingested microplastics (Stasolla et al. 2015).

Although microplastic ingestion among crabs is high, it may not follow a similar pattern to that of $N$. norvegicus, given that, unlike $N$. norvegicus, male crabs ingest more microplastics than females (Wójcik-Fudalewska et al. 2016). The effects of ecdysis and crab size on the amount of ingested microplastics have not been determined, but it is possible that ecdysis may play an important role in ridding crabs of ingested microplastic in a similar fashion to $N$. norvegicus.

\section{Fish}

Fish in the marine environment are amply exposed to microplastics in the water column, in sediment and in contaminated prey items (Steer et al. 2017, Sun et al. 2017, Halstead et al. 2018). Since microplastics are frequently encountered drifting in the water column or mixed with sediments, the ingestion of these small plastic particles could occur unintentionally during foraging. Fishes have the capacity to not only consume, but also sequester and cycle microplastics. Quantitatively, the average amount of microplastics ingested may increase as the size of the fish increases, until a certain maximum for both plastic and fish size is reached, after which this equivalency between quantity of plastic ingested and fish size may no longer be consistent (Boerger et al. 2010). The ingestion of plastics by marine organisms is often reported as 'mistaken identity' ingestion, and this occurs partly as a result of the resemblance of plastic fragments to the natural prey of many marine organisms. However, the predatory feeding mechanisms of fish, including opportunist strategies, occasional swift feeding strikes and ingestion of contaminated prey items, may result in the consumption of microplastics via trophic links (Battaglia et al. 2013).

As is the case with many marine invertebrates, the feeding behavior of a fish affects the size and quantity of the microplastics it ingests. Omnivorous fish, often categorized as both generalists and opportunists, are capable of switching between animal and plant food sources. They feed on a wider variety of food items, and therefore, it is not surprising that they ingest more microplastic particles than strictly carnivorous or herbivorous fish (Mizraji et al. 2017). Most carnivorous fish have large jaws, and their teeth are adapted to procuring and consuming prey. They therefore consume active prey, which may include other fishes and mobile invertebrates (Butler 1994). Characterized by an elongated fusiform shape, many carnivorous fishes are built for speed, either to pursue and capture prey, or to escape from other predators. These characteristics of carnivorous fish may in part explain why they consume fewer microplastic particles, since microplastics are either floating particles in the water column or drift along with ocean currents as opposed to actively swimming 
prey items. The ingestion of microplastics by carnivorous fish may therefore occur as a result of consuming already contaminated prey items. In contrast, herbivorous and omnivorous fishes typically have small terminal mouths, with reduced, modified or no teeth. Their bodies are generally laterally compressed, with modified fins that enable precise control of their body position during continuous grazing episodes (Choat \& Bellwood 1991, Butler 1994). Herbivorous and omnivorous fishes therefore feed largely on plants and sessile or slow-moving organisms, so drifting microplastics in the water column may be mistaken for food materials.

\section{Large animals and mammals}

Tiny as microplastics may be, their impacts are felt by even the largest creatures of the marine world. Baleen whales such as humpbacks Megaptera novaeangliae that feed by filtering small food particles out of large volumes of water are at great risk of ingesting microplastics that are drifting in the marine environment. Some humpback whales possess preferential and lunge feeding styles that enable them to focus on a school of prey (Fossi et al. 2012), potentially ingesting drifting microplastics in the water column and in their prey items. With a high concentration of microplastics in the habitats and feeding grounds of these marine megafauna (Fossi et al. 2016), their ingestion of microplastics is almost inevitable.

The ingestion of microplastics by whales is thought to contribute to the chemical contaminant load of the animals. Indeed, marine chemical contaminants were detected in the blubber a of baleen whale and the muscle and skin of a whale shark Rhincodon typus that had previously ingested microplastics (Fossi et al. 2016, 2017). However, since marine organisms are able to pick up chemical contaminants directly from ambient waters and from contaminated prey, it is not clear how much of the contaminants detected in the animals were the result of microplastic ingestion. Monitoring the presence and concentration of chemical contaminants in these animals was therefore suggested as a way of obtaining valuable information on the extent and impact of microplastic pollution in the marine environment.

Opportunities to study microplastic ingestion by marine mammals are rare; therefore, at the time of this writing, studies relating to microplastic ingestion by marine megafauna have only been carried out on stranded animals. The examination of the gut contents of stranded whales reveals what the diet of the animals consisted of prior to being stranded. Their diet often comprised mesopelagic fish, cephalopods and microplastics, of which the plastic particles were present throughout the entire gastrointestinal tract. The presence of microplastics in all sections of the digestive tract of whales may suggest that ingested microplastics are eventually excreted. It is noteworthy, however, that some stranded whales, including a True's beaked whale Mesoplodon mirus and a Cuvier's beaked whale Ziphius cavirostris, contained only plastic items in their stomach but not food (Santos et al. 2001, Souza et al. 2005). This then raises questions about the ability of whales to excrete ingested plastic materials and the potential for ingested plastic items to cause gastrointestinal blockage in cetaceans. Furthermore, it has yet to be determined whether some whales, such as filter feeding baleen whales, are able to excrete ingested plastic particles while some others, including beaked whales, are unable to excrete the plastic fragments they ingest. It is also not known whether the size of ingested plastic materials affects the ability of whales to egest the debris and whether gastrointestinal blockage is related to the size of the plastic debris that whales ingest. These questions may remain unanswered because of the rarity of opportunities to study microplastic ingestion in the organisms.

Between 1990 and 2015, a total of 2934 cetacean strandings were recorded around the world; of 528 stranded individuals examined for microplastics, 21 contained anthropogenic debris (Lusher et al. 2018). It is conceivable that filter feeding marine megafauna ingest microplastics in significant quantities due mainly to their filter feeding behaviors; however, non-filter feeding marine mammals such as seals and sea lions have also been reported to have ingested microplastics (Bravo Rebolledo et al. 2013). Since seals are carnivores and would first capture their prey before ingesting it whole, they are unlikely to directly ingest drifting or sedimented microplastics in the marine environment. Hence, the most likely means by which seals may ingest microplastics is through the accidental consumption of contaminated food items while foraging on burrowing or bottom-dwelling prey. Trophic transfer is therefore implicated in the ingestion of microplastics by seals. Since the diet of seals comprises predominantly fish, the ingestion of microplastics by seals is more likely a result of foraging on lanternfish and other prey that have previously ingested the micro-debris. 


\section{TROPHIC TRANSFER OF MICROPLASTICS}

The transfer of microplastics across trophic levels in the wild is inevitable because a number of marine animals directly ingest plastic micro-debris that is either adrift or associated with sediment in the marine environment. Laboratory experiments have demonstrated that microplastics can be transferred across trophic levels (Farrell \& Nelson 2013, Setälä et al. 2014). Furthermore, the incidence of microplastic ingestion by marine carnivores is indicative of the occurrence of microplastic trophic transfer in natural marine habitats. This is because many marine carnivorous organisms often consume active prey as opposed to floating or slowly-drifting plastic particles (Butler 1994). Marine top predators were reported to have ingested microplastics from previously contaminated fish prey, and a strong correlation between microplastics consumed by fish and those found in the scats of top predators was demonstrated (Nelms et al. 2018). Trophic transfer may therefore represent an indirect and yet significant pathway through which microplastics are ingested by predatory species whose feeding behavior involves the consumption of whole prey (Nelms et al. 2018). When organisms at lower trophic levels ingest microplastics, they may retain the micro-debris for a while before egesting it. The residence time of microplastics in the gut of zooplankton and other organisms at lower trophic levels would play an important role in determining both the amount of microplastics that is transferred and the rate of microplastic transfer up the marine food pyramid. Therefore, the longer the residence time of microplastics in prey organisms, the higher the chances of microplastic trophic transfer to predatory species (Au et al. 2017).

The gut residence time of microplastics in zooplankton could be up to a few hours, although this time may decrease with increasing food concentration. Conversely, if the concentration of food is low, then organisms may retain ingested microplastics for longer periods. It could then be hypothesized that when food is in short supply, marine fauna are more likely to ingest and retain microplastics for a longer time, thereby increasing the chances of microplastic transfer to organisms at higher trophic levels. Further, microplastics can form aggregates in the gut of zooplankton, resulting in a longer retention time and a slower egestion rate (Ogonowski et al. 2016). Aggregate formation, just like inadequate food supply, could therefore play an important role in the trophic transfer of microplastics from zooplankton to other organisms that prey on them.
The retention of microplastics often occurs in the gut, but it was reported that microplastics that were transferred across trophic levels, through translocation, can be retained in the hemolymph, hepatopancreas, ovaries and gills of crabs (Farrell \& Nelson 2013). The retention of trophically transferred microplastics in the tissues and organs of marine organisms makes microplastic transfer further up the marine food chain more likely and threatens the survival of the organisms that retain the debris. Since microplastics in the marine environment are able to adsorb and concentrate waterborne chemical pollutants up to 1 million times more than the background pollutant concentration of surrounding seawater (Mato et al. 2001), the ingestion of such microplastics, and consequently, their trophic transfer, could potentially lead to the bioaccumulation and biomagnification of POPs in top predators.

\section{EFFECTS OF MICROPLASTIC INGESTION}

Microplastic prevalence in the marine environment and its attendant consequences are important focal points of environmental research. Table 1 summarizes some of the effects of microplastic ingestion on marine organisms. The physical effects of microplastic ingestion on organisms in situ are largely unknown, but digestive tract obstruction and blockage, internal abrasion and ulceration are possible physical consequences of microplastic ingestion in the natural marine environment. Obstruction and blockage of the digestive tract could result in a feeling of satiation, starvation and physical deterioration, which could in turn lead to diminished reproductive fitness, reduced predator avoidance and escape, impaired feeding ability, nutrient dilution, reduced growth rate and absorption of toxins, all of which may eventually lead to the death of the organism (Galgani et al. 2010, Cole et al. 2013, Wright et al. 2013b).

\section{Mollusks}

The ingestion of microplastics by bivalve mollusks could lead to a significant decrease in lysosomal membrane stability and a significant increase in the formation of tight ball-like collections of immune cells referred to as granulocytomas (von Moos et al. 2012). As a non-neoplastic inflammatory cellular condition in marine mussels, granulocytoma is capable of overcoming host encapsulation and inducing atro- 


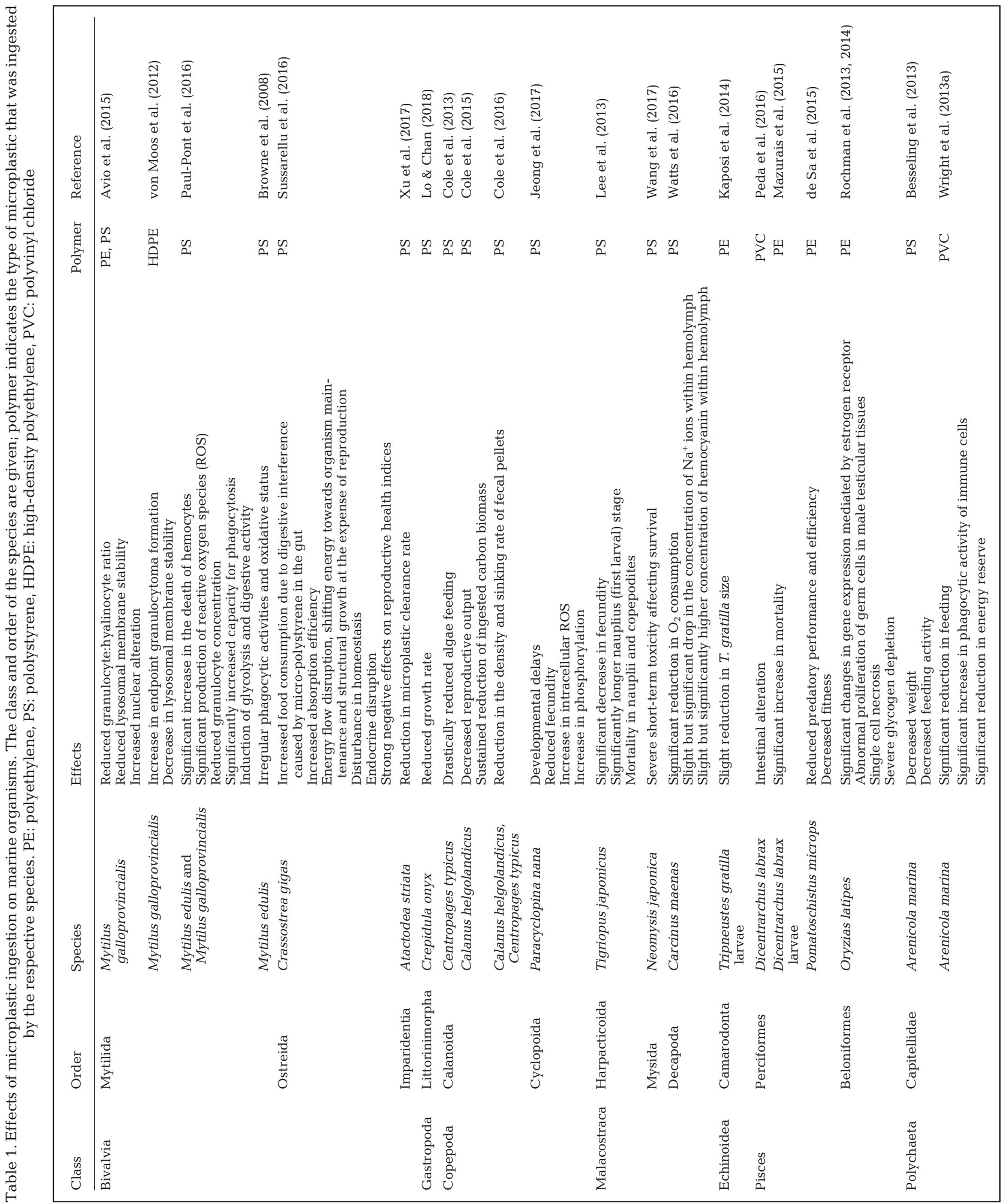


phy and autolysis of the digestive gland, thereby representing a terminal condition (Lowe \& Moore 1979). Also, ingested microplastics are capable of translocating to the hemolymph and circulatory system of marine mussels with the possibility of exerting physiological stress on the organism (Browne et al. 2008). The presence of microplastics in the hemolymph could lead to increased hemocyte mortality. An increase in the mortality of hemocytes could in turn trigger the production of reactive oxygen species (Paul-Pont et al. 2016). Important functions of the hemocytes such as phagocytosis and pathogen elimination could be adversely affected by microplastic ingestion. Also, since hemocytes participate in vital processes such as shell formation (Mount et al. 2004) and wound healing (Franchini \& Ottaviani 2000), their ability to function in these roles may be hampered by the presence of microplastics in the hemolymph. Further, microplastic ingestion could negatively impact the fecundity and energy allocation of some bivalves, such that energy is allocated to the maintenance and structural growth of the organism at the expense of reproduction, thereby impairing gametogenesis and the gamete quality of the animal (Sussarellu et al. 2016). This in turn could negatively affect the population and survival of bivalves.

\section{Crustaceans}

Developmental delays, reduced fecundity and delayed molting are possible effects of microplastics on crustaceans (Jeong et al. 2017). Moreover, microplastic ingestion could lead to increased mortality of nauplii and copepodites, thereby inducing a significant reduction in the survival of juvenile crustaceans (Lee et al. 2013).

A significant reduction in oxygen consumption, reduced concentration of $\mathrm{Na}^{+}$, increased concentrations of $\mathrm{Ca}^{2+}$ and increased hemocyanin within the hemolymph are some of the likely effects of microplastic ingestion on shore crabs (Watts et al. 2016). Therefore, microplastic ingestion can potentially negatively affect important functions of the immune cells of crabs. The mechanisms by which microplastics exert these effects on crustaceans are unclear, but it should be noted that in almost every controlled laboratory experiment that demonstrated the adverse effects of microplastics on marine organisms, the microplastic concentrations employed were orders of magnitude higher than current microplastic concentration in marine environments. Most of these effects were a result of short-term, high-concentration exposures, which may prevent the extrapolation of data to a more realistic and environmentally relevant scenario.

\section{Fish}

Fish have been widely reported to ingest microplastics in controlled laboratory experiments with resultant effects that range from increased mortality (Mazurais et al. 2015), intestinal blockage and reduced predatory efficiency (de Sa et al. 2015), to hepatic stress including severe glycogen depletion, significant changes in estrogen-receptor-mediated gene expression, single-cell necrosis and abnormal proliferation of germ cells in male testicular tissues of fish (Rochman et al. 2013, 2014). Long-term exposure to microplastics could lead to significant intestinal alteration as well as structural and functional modifications of the fish intestine (Pedà et al. 2016). These effects could subsequently result in a significant impairment of fish development during early life stages, thereby adversely affecting reproductive success, population size and survival of the organisms.

\section{Neoplasia in marine species}

Neoplasia in marine organisms did not gain much attention until recently when sea lion genital carcinoma and sea turtle fibropapillomatosis were identified and reported to be widespread. Cancer among marine wildlife is on the rise (Newman \& Smith 2006, Erren et al. 2013), and the incidence of neoplasia has already reached epizootic proportions in beluga whales Delphinapterus leucas (De Guise et al. 1994). The high incidence of cancer reported in wildlife populations occurred in areas contaminated with anthropogenic pollutants. However, the global nature of the incidence of neoplasia in marine species suggests that global contaminants, such as microplastics in all varieties, may be involved (McAloose \& Newton 2009, Meyer-Rochow et al. 2015). Indeed, endocrine disruption, including the abnormal proliferation of testicular germ cells and alterations in estrogen-mediated gene expression, were observed in fishes that had experimentally ingested polyethylene microplastics (Rochman et al. 2014). Such alterations in gene expression mediated by the estrogen receptor may potentially lead to neoplastic growth via epigenetic pathways. Furthermore, endocrine disruptors and xenoestrogenic chemicals like bisphe- 
nol A (BpA) are important components in the synthesis of plastics. BpA has been experimentally linked to the development of cancer in fetal and neonatal rodents via epigenetic programming (Prins et al. 2007). However, that study was carried out in rodents, and it is not known whether such a link between BpA and cancer development exists in marine species. Therefore, the relationship between cancer incidents in marine wildlife and microplastic abundance require increased attention mainly because of the risk that anthropogenic debris poses to both marine wildlife and humans. Also, the role of chemical additives and sorbed contaminants in the increased incidents of neoplasia among marine animals is yet to be determined.

\section{CONCLUSION AND HYPOTHETICAL QUESTIONS}

Microplastic contamination in biota-rich waters and sediments is inevitably leading to the ingestion of plastic micro-debris. The widespread nature of microplastic ingestion by marine organisms and its potential consequences are frequently being demonstrated both in situ and in controlled laboratory experiments. At the bottom of the marine trophic pyramid are primary producers, including algae, that are capable of forming aggregates with microplastics (Long et al. 2017). When zooplankton ingest prey items that are aggregated to microplastics, it can lead to the transfer of the micro-debris to organisms that are higher up in the marine trophic pyramid. Moreover, the ingestion of small plastic particles that adsorb marine chemical contaminants presents a probable path for the entrance of organic pollutants into the marine food web, with the possibility of bioaccumulation and biomagnification at higher trophic levels (Avio et al. 2015).

Although controlled laboratory studies employ very high levels of microplastics that exceed concentrations found in most polluted marine environments, they clearly reveal some of the potentially harmful effects that microplastics may have on marine organisms. The implications of microplastic ingestion on the health and survival of marine organisms remain unclear for the most part, and hence there is need for further studies. This review has addressed a number of cogent questions that should lead to more research into the harmful effects of the increasing presence of microplastics in the marine environment, and some specific hypothetical questions are proposed below.
(1) Can the current and projected amounts of microplastics in biota-rich waters significantly affect keystone species? Microplastics are ubiquitous in the marine environment, and with continued improper disposal of plastic wastes, the amount of small plastic fragments in the ocean will steadily rise. Keystone species near the bottom of the marine food pyramid, including krill and other zooplankton, consume microplastics in the marine environment, and laboratory-scale experiments have shown that microplastic ingestion can have significant negative effects on the survival and energetics of these species that determine the trophic structure of marine ecosystems (Lee et al. 2013, Cole et al. 2015). This in turn might affect the supply of nutrients and energy to predators such as whales, seals, fishes and squids at higher trophic levels. The question then arises whether the current and projected microplastic load of biota-rich marine ecosystems will at some point begin to adversely impact species that either directly or indirectly ingest this anthropogenic debris, thereby affecting the trophic transfer of energy.

(2) Does gut aggregate formation increase microplastic retention? Microplastics form aggregates with marine microalgae which are at the base of most marine food pyramids (Zhang et al. 2017). Microplastic ingestion rates could be increased by aggregate formation, potentially leading to trophic transfer of microplastics. Moreover, ingested microplastics can form aggregates in the gut of small aquatic crustaceans, and this might result in prolonged gut retention of microplastics, further increasing the chances of microplastic trophic transfer. This then raises the question of whether the ingestion of algae-microplastic aggregates, or the formation of microplastic aggregates in the gut of marine fauna, will lead to prolonged gut retention and subsequent trophic transfer of plastic micro-debris.

(3) Do chemical pollutants adsorbed onto microplastics biomagnify in marine food webs? The concurrent abundance of microplastics and POPs in the marine environment unavoidably result in the adsorption of marine pollutants onto microplastics. Even though marine organisms are known to contain these toxic pollutants, it is not clear whether the toxins were transferred to the organisms via ingestion of microplastics, or via ingestion of POP-contaminated prey, or whether the organic pollutants were absorbed directly from ambient marine waters. Therefore, there is need for further research in order to determine whether the ingestion of microplastics by marine organisms could lead to the biomagnification of organic pollutants in higher trophic levels. Addi- 
tionally, the concentration of accumulated organic pollutants in organisms may be in equilibrium with pollutant concentrations in surrounding sea waters (Davison \& Asch 2011). As such, it is important to determine if this equilibrium state is affected by the ingestion of contaminated microplastics and by the ingestion of already contaminated organisms. This in turn would demonstrate the effects of biomagnification on the equilibrium state of contaminants in marine organisms.

Acknowledgements. Many thanks to the Faculty of Science, University of Malaya, for financial support under grant RF005B-2018, and to the anonymous reviewers whose suggestions helped improve earlier versions of the manuscript.

\section{LITERATURE CITED}

Allen AS, Seymour AC, Rittschof D (2017) Chemoreception drives plastic consumption in a hard coral. Mar Pollut Bull 124:198-205

Alomar C, Estarellas F, Deudero S (2016) Microplastics in the Mediterranean Sea: deposition in coastal shallow sediments, spatial variation and preferential grain size. Mar Environ Res 115:1-10

$\mathrm{Au}$ SY, Lee CM, Weinstein JE, van den Hurk P, Klaine SJ (2017) Trophic transfer of microplastics in aquatic ecosystems: identifying critical research needs. Integr Environ Assess Manag 13:505-509

Avio CG, Gorbi S, Milan M, Benedetti M and others (2015) Pollutants bioavailability and toxicological risk from microplastics to marine mussels. Environ Pollut 198: 211-222

Ayukai T (1987) Discriminate feeding of the calanoid copepod Acartia clausi in mixtures of phytoplankton and inert particles. Mar Biol 94:579-587

Battaglia P, Andaloro F, Consoli P, Esposito V and others (2013) Feeding habits of the Atlantic bluefin tuna, Thunnus thynnus (L. 1758), in the central Mediterranean Sea (Strait of Messina). Helgol Mar Res 67:97-107

Besseling E, Wegner A, Foekema EM, van den HeuvelGreve MJ, Koelmans AA (2013) Effects of microplastic on fitness and PCB bioaccumulation by the lugworm Arenicola marina (L.). Environ Sci Technol 47:593-600

Boerger CM, Lattin GL, Moore SL, Moore CJ (2010) Plastic ingestion by planktivorous fishes in the North Pacific Central Gyre. Mar Pollut Bull 60:2275-2278

Bravo Rebolledo EL, Van Franeker JA, Jansen OE, Brasseur SMJM (2013) Plastic ingestion by harbour seals (Phoca vitulina) in The Netherlands. Mar Pollut Bull 67:200-202

Brennecke D, Ferreira EC, Costa TMM, Appel D, da Gama BAP, Lenz M (2015) Ingested microplastics (>100 $\mu \mathrm{m})$ are translocated to organs of the tropical fiddler crab $U_{C a}$ rapax. Mar Pollut Bull 96:491-495

Brillant MGS, MacDonald BA (2000) Postingestive selection in the sea scallop, Placopecten magellanicus (Gmelin): the role of particle size and density. J Exp Mar Biol Ecol 253:211-227

Browne MA, Dissanayake A, Galloway TS, Lowe DM, Thompson RC (2008) Ingested microscopic plastic translocates to the circulatory system of the mussel, Mytilus edulis (L.). Environ Sci Technol 42:5026-5031

Butler VL (1994) Fish feeding behaviour and fish capture: the case for variation in Lapita fishing strategies. Archaeol Ocean 29:81-90

Choat J, Bellwood D (1991) Reef fishes: their history and evolution. In: Sale PF (ed) The ecology of fishes on coral reefs. Academic Press Inc., , p 39-66

Claessens M, De Meester S, Van Landuyt L, De Clerck K, Janssen CR (2011) Occurrence and distribution of microplastics in marine sediments along the Belgian coast. Mar Pollut Bull 62:2199-2204

Cole M, Lindeque P, Fileman E, Halsband C, Goodhead R, Moger J, Galloway TS (2013) Microplastic ingestion by zooplankton. Environ Sci Technol 47:6646-6655

Cole M, Lindeque P, Fileman E, Halsband C, Galloway TS (2015) The impact of polystyrene microplastics on feeding, function and fecundity in the marine copepod Calanus helgolandicus. Environ Sci Technol 49: 1130-1137

Cole M, Lindeque PK, Fileman E, Clark J, Lewis C, Halsband C, Galloway TS (2016) Microplastics alter the properties and sinking rates of zooplankton faecal pellets. Environ Sci Technol 50:3239-3246

Davison P, Asch RG (2011) Plastic ingestion by mesopelagic fishes in the North Pacific Subtropical Gyre. Mar Ecol Prog Ser 432:173-180

de Sa LC, Luis LG, Guilhermino L (2015) Effects of microplastics on juveniles of the common goby (Pomatoschistus microps): confusion with prey, reduction of the predatory performance and efficiency, and possible influence of developmental conditions. Environ Pollut 196:359-362

De Guise S, Lagacé A, Béland P (1994) Tumors in St. Lawrence beluga whales (Delphinapterus leucas). Vet Pathol 31:444-449

Erren T, Zeuss D, Steffany F, Meyer-Rochow V (2013) Oceans of plastics: possible risks of cancer in marine wildlife and humans. In: Allodi S (ed) Exploring themes on aquatic toxicology. Research Signpost, Trivandrum, p 51-74

Farrell P, Nelson K (2013) Trophic level transfer of microplastic: Mytilus edulis (L.) to Carcinus maenas (L.). Environ Pollut 177:1-3

Fazey FMC, Ryan PG (2016) Biofouling on buoyant marine plastics: an experimental study into the effect of size on surface longevity. Environ Pollut 210:354-360

Fischer V, Elsner NO, Brenke N, Schwabe E, Brandt A (2015) Plastic pollution of the Kuril-Kamchatka Trench area (NW pacific). Deep Sea Res II Top Stud Oceanogr 111:399-405

Fossi MC, Panti C, Guerranti C, Coppola D, Giannetti M, Marsili L, Minutoli R (2012) Are baleen whales exposed to the threat of microplastics? A case study of the Mediterranean fin whale (Balaenoptera physalus). Mar Pollut Bull 64:2374-2379

Fossi MC, Marsili L, Baini M, Giannetti M and others (2016) Fin whales and microplastics: the Mediterranean Sea and the Sea of Cortez scenarios. Environ Pollut 209: $68-78$

Fossi MC, Baini M, Panti C, Galli M and others (2017) Are whale sharks exposed to persistent organic pollutants and plastic pollution in the Gulf of California (Mexico)? First ecotoxicological investigation using skin biopsies. Comp Biochem Physiol C Toxicol Pharmacol 199:48-58 
Franchini A, Ottaviani E (2000) Repair of molluscan tissue injury: role of PDGF and TGF- $\beta$. Tissue Cell 32:312-321

Frias JPGL, Otero V, Sobral P (2014) Evidence of microplastics in samples of zooplankton from Portuguese coastal waters. Mar Environ Res 95:89-95

Galgani F, Fleet D, van Franeker JA, Katsanevakis S and others (2010) Marine Strategy Framework directive-Task Group 10 Report. Marine litter do not cause harm to the coastal and marine environment. Report on the identification of descriptors for the Good Environmental Status of European Seas regarding marine litter under the Marine Strategy Framework Directive. Office for Official Publications of the European Communities, Luxembourg

Halstead JE, Smith JA, Carter EA, Lay PA, Johnston EL (2018) Assessment tools for microplastics and natural fibres ingested by fish in an urbanised estuary. Environ Pollut 234:552-561

Jeong CB, Kang HM, Lee MC, Kim DH and others (2017) Adverse effects of microplastics and oxidative stressinduced MAPK/Nrf2 pathway-mediated defense mechanisms in the marine copepod Paracyclopina nana. Sci Rep 7:41323

Kaposi KL, Mos B, Kelaher BP, Dworjanyn SA (2014) Ingestion of microplastic has limited impact on a marine larva. Environ Sci Technol 48:1638-1645

Kiørboe T (2011) How zooplankton feed: mechanisms, traits and trade-offs. Biol Rev Camb Philos Soc 86:311-339

Lee KW, Shim WJ, Kwon OY, Kang JH (2013) Size-dependent effects of micro polystyrene particles in the marine copepod Tigriopus japonicus. Environ Sci Technol 47: 11278-11283

Lo HKA, Chan KYK (2018) Negative effects of microplastic exposure on growth and development of Crepidula onyx. Environ Pollut 233:588-595

Long M, Paul-Pont I, Hegaret H, Moriceau B, Lambert C, Huvet A, Soudant P (2017) Interactions between polystyrene microplastics and marine phytoplankton lead to species-specific hetero-aggregation. Environ Pollut 228: 454-463

Lowe DM, Moore MN (1979) The cytology and occurrence of granulocytomas in mussels. Mar Pollut Bull 10: $137-141$

Lusher AL (2015) Microplastics in the marine environment: distribution, interactions and effects. In: Bergmann $M$ Gutow L, Klages M (eds) Marine anthropogenic litter Springer International Publishing, Cham, p 245-307

Lusher AL, O'Donnell C, Officer R, O'Connor I (2016) Microplastic interactions with North Atlantic mesopelagic fish. ICES J Mar Sci 73:1214-1225

Lusher AL, Hernandez-Milian G, Berrow S, Rogan E, O'Connor I (2018) Incidence of marine debris in cetaceans stranded and bycaught in Ireland: recent findings and a review of historical knowledge. Environ Pollut 232:467-476

Mathalon A, Hill P (2014) Microplastic fibers in the intertidal ecosystem surrounding Halifax Harbor, Nova Scotia. Mar Pollut Bull 81:69-79

Mato Y, Isobe T, Takada H, Kanehiro H, Ohtake C, Kaminuma T (2001) Plastic resin pellets as a transport medium for toxic chemicals in the marine environment. Environ Sci Technol 35:318-324

Mazurais D, Ernande B, Quazuguel P, Severe A and others (2015) Evaluation of the impact of polyethylene microbeads ingestion in European sea bass (Dicentrarchus labrax) larvae. Mar Environ Res 112:78-85
McAloose D, Newton AL (2009) Wildlife cancer: a conservation perspective. Nat Rev Cancer 9:517-526

Meyer-Rochow VB, Gross JV, Steffany F, Zeuss D, Erren TC (2015) Commentary. Plastic ocean and the cancer connection: 7 questions and answers. Environ Res 142: 575-578

Mizraji R, Ahrendt C, Perez-Venegas D, Vargas J and others (2017) Is the feeding type related with the content of microplastics in intertidal fish gut? Mar Pollut Bull 116: 498-500

Mount AS, Wheeler AP, Paradkar RP, Snider D (2004) Hemocyte-mediated shell mineralization in the eastern oyster. Science 304:297-300

Nadal MA, Alomar C, Deudero S (2016) High levels of microplastic ingestion by the semipelagic fish bogue Boops boops (L.) around the Balearic Islands. Environ Pollut 214:517-523

Nelms SE, Galloway TS, Godley BJ, Jarvis DS, Lindeque PK (2018) Investigating microplastic trophic transfer in marine top predators. Environ Pollut 238:999-1007

Newman SJ, Smith SA (2006) Marine mammal neoplasia: a review. Vet Pathol 43:865-880

Ogonowski M, Schür C, Jarsén Å, Gorokhova E (2016) The effects of natural and anthropogenic microparticles on individual fitness in Daphnia magna. PLOS ONE 11: e0155063

Paul-Pont I, Lacroix C, González-Fernández C, Hégaret H and others (2016) Exposure of marine mussels Mytilus spp. to polystyrene microplastics: toxicity and influence on fluoranthene bioaccumulation. Environ Pollut 216: 724-737

Pedà C, Caccamo L, Fossi MC, Gai F and others (2016) Intestinal alterations in European sea bass Dicentrarchus labrax (Linnaeus, 1758) exposed to microplastics: preliminary results. Environ Pollut 212:251-256

PlasticsEurope (2017) Plastics - the facts 2017. An analysis of European plastics production, demand and waste data. Plastics Europe, Brussels

Prins GS, Birch L, Tang WY, Ho SM (2007) Developmental estrogen exposures predispose to prostate carcinogenesis with aging. Reprod Toxicol 23:374-382

Rice MR, Gold HS (1984) Polypropylene as an adsorbent for trace organics in water. Anal Chem 56:1436-1440

Rochman CM, Hoh E, Kurobe T, Teh SJ (2013) Ingested plastic transfers hazardous chemicals to fish and induces hepatic stress. Sci Rep 3:3263

Rochman CM, Kurobe T, Flores I, Teh SJ (2014) Early warning signs of endocrine disruption in adult fish from the ingestion of polyethylene with and without sorbed chemical pollutants from the marine environment. Sci Total Environ 493:656-661

Ryan PG (2015) Does size and buoyancy affect the long-distance transport of floating debris? Environ Res Lett 10: 084019

Sailley SF, Polimene L, Mitra A, Atkinson A, Allen JI (2015) Impact of zooplankton food selectivity on plankton dynamics and nutrient cycling. J Plankton Res 37:519-529

Santos MB, Pierce GJ, Herman J, Lopez A, Guerra A, Mente E, Clarke MR (2001) Feeding ecology of Cuvier's beaked whale (Ziphius cavirostris): a review with new information on the diet of this species. J Mar Biol Assoc UK 81: 687-694

Setälä O, Fleming-Lehtinen V, Lehtiniemi M (2014) Ingestion and transfer of microplastics in the planktonic food web. Environ Pollut 185:77-83 
Setälä O, Norkko J, Lehtiniemi M (2016) Feeding type affects microplastic ingestion in a coastal invertebrate community. Mar Pollut Bull 102:95-101

Souza SP, Siciliano S, Cuenca S, Sanctis B (2005) A True's beaked whale (Mesoplodon mirus) on the coast of Brazil: adding a new beaked whale species to the Western Tropical Atlantic and South America. Lat Am J Aquat Mamm 4:129-136

Stasolla G, Innocenti G, Galil BS (2015) On the diet of the invasive crab Charybdis longicollis Leene, 1938 (Brachyura: Portunidae) in the eastern Mediterranean Sea. Isr J Ecol Evol 61:130-134

Steer M, Cole M, Thompson RC, Lindeque PK (2017) Microplastic ingestion in fish larvae in the western English Channel. Environ Pollut 226:250-259

Sun X, Li Q, Zhu M, Liang J, Zheng S, Zhao Y (2017) Ingestion of microplastics by natural zooplankton groups in the northern South China Sea. Mar Pollut Bull 115:217-224

Sussarellu R, Suquet M, Thomas Y, Lambert C and others (2016) Oyster reproduction is affected by exposure to polystyrene microplastics. Proc Natl Acad Sci USA 113: 2430-2435

Teuten EL, Rowland SJ, Galloway TS, Thompson RC (2007) Potential for plastics to transport hydrophobic contaminants. Environ Sci Technol 41:7759-7764

Teuten EL, Saquing JM, Knappe DRU, Barlaz MA and others (2009) Transport and release of chemicals from plastics to the environment and to wildlife. Philos Trans R Soc B 364:2027-2045

Van Cauwenberghe L, Janssen CR (2014) Microplastics in bivalves cultured for human consumption. Environ Pollut 193:65-70

Van Cauwenberghe L, Claessens M, Vandegehuchte MB, Janssen CR (2015) Microplastics are taken up by mussels (Mytilus edulis) and lugworms (Arenicola marina) living in natural habitats. Environ Pollut 199:10-17

von Moos N, Burkhardt-Holm P, Kohler A (2012) Uptake and effects of microplastics on cells and tissue of the blue mussel Mytilus edulis L. after an experimental exposure. Environ Sci Technol 46:11327-11335

Wang J, Tan Z, Peng J, Qiu Q, Li M (2016) The behaviors of

Editorial responsibility: Victor Benno Meyer-Rochow, Oulu, Finland microplastics in the marine environment. Mar Environ Res 113:7-17

Wang M, Wang X, Luo X, Zheng H (2017) Short-term toxicity of polystryrene microplastics on mysid shrimps Neomysis japonica. IOP Conference Series: Earth and Environmental Science 61:012136

Ward JE, Shumway SE (2004) Separating the grain from the chaff: particle selection in suspension- and depositfeeding bivalves. J Exp Mar Biol Ecol 300:83-130

Watts AJR, Urbina MA, Goodhead R, Moger J, Lewis C, Galloway TS (2016) Effect of microplastic on the gills of the shore crab Carcinus maenas. Environ Sci Technol 50: 5364-5369

Welden NAC, Cowie PR (2016) Environment and gut morphology influence microplastic retention in langoustine, Nephrops norvegicus. Environ Pollut 214:859-865

Wójcik-Fudalewska D, Normant-Saremba M, Anastácio P (2016) Occurrence of plastic debris in the stomach of the invasive crab Eriocheir sinensis. Mar Pollut Bull 113: 306-311

Woodall LC, Sanchez-Vidal A, Canals M, Paterson GLJ and others (2014) The deep sea is a major sink for microplastic debris. R Soc Open Sci 1:140317

Wright SL, Rowe D, Thompson RC, Galloway TS (2013a) Microplastic ingestion decreases energy reserves in marine worms. Curr Biol 23:R1031-R1033

Wright SL, Thompson RC, Galloway TS (2013b) The physical impacts of microplastics on marine organisms: a review. Environ Pollut 178:483-492

Xu XY, Lee WT, Chan AKY, Lo HS, Shin PKS, Cheung SG (2017) Microplastic ingestion reduces energy intake in the clam Atactodea striata. Mar Pollut Bull 124:798-802

Yokota K, Waterfield H, Hastings C, Davidson E, Kwietniewski E, Wells B (2017) Finding the missing piece of the aquatic plastic pollution puzzle: interaction between primary producers and microplastics. Limnol Oceanogr Lett 2:91-104

Zhang C, Chen XH, Wang JT, Tan LJ (2017) Toxic effects of microplastic on marine microalgae Skeletonema costatum: interactions between microplastic and algae. Environ Pollut 220:1282-1288

Submitted: March 15, 2018; Accepted: July 19, 2018 Proofs received from author(s): September 11, 2018 